\title{
Juvenile inflammatory arthritis: Development and validation of an illustrated questionnaire for measurement of children's and adolescents' motivation
}

\author{
El Miedany $\mathbf{Y}^{1,2^{*}}$, Lotfy $\mathrm{H}^{3}$, Mortada $\mathrm{M}^{4}$, El Aroussy $\mathrm{N}^{1}$, Mekkawy $\mathrm{D}^{1}$, Salah $\mathrm{W}^{5}$, Nasef SI ${ }^{6}$, Eissa $^{7}$, Hassan $\mathrm{M}^{8}$, Farag $\mathrm{Y}^{3}$, Bahlas $\mathrm{S}^{9}$ and \\ E1 Gaafary M $\mathbf{M}^{10}$ \\ ${ }^{1}$ Department of Rheumatology and Rehabilitation, School of Medicine, Ain Shams University, Cairo, Egypt \\ ${ }^{2}$ Department of Rheumatology, Darent Valley Hospital, Dartford, United Kingdom \\ ${ }^{3}$ Department of Pediatrics, School of Medicine, Cairo University, Cairo, Egypt \\ ${ }^{4}$ Department of Rheumatology and Rehabilitation, Zagazig University, Egypt \\ ${ }^{5}$ Department of Rheumatology and Rehabilitation, School of Medicine, Banha University, Banha, Egypt \\ ${ }^{6}$ Department of Rheumatology and Rehabilitation, School of Medicine, Suez Canal University, Ismaillia, Egypt \\ ${ }^{7}$ Department of Rheumatology and Rehabilitation, School of Medicine, Cairo University, Egypt \\ ${ }^{8}$ Department of Rheumatology and Rehabilitation, Tanta University, Egypt \\ ${ }^{9}$ Department of Rheumatology, King Abdul Aziz University, Jeddah, Sadui Arabia \\ ${ }^{10}$ Department of Community and Public Health, School of Medicine, Ain Shams University, Cairo, Egypt
}

\begin{abstract}
Objectives: To develop and assess the psychometric properties of an instrument/questionnaire for evaluation of "motivation" amongst children and adolescents living with inflammatory arthritic conditions.

Methods: Based on content analysis, semi structured group discussion and Rasch analysis, ten domains were identified, hence, the questionnaire was developed including: 10-items scale (0-10 on VAS scale). Each item was supported by illustrations explaining both ends of the measure. Construct validity was assessed by correlating the score of the questionnaire to disease activity scores; patient reported outcomes; as well as adherence to therapy. Reliability and comprehensibility and sensitivity to change were also assessed.

Results: The questionnaire was assessed in 142 children (43 JIA, 33 systemic arthritis, 34 enthesitis related arthritis, 32 cSLE) Results revealed that the developed illustrated questionnaire mean score correlated significantly $(\mathrm{p}<0.001)$ with disease activity measures: JADAS-27, SLEDAI-2K and JSpADA, reflecting its validity. It also correlated significantly $(\mathrm{p}<0.001)$ with the scores of functional disabilities, health related quality of life and medication adherence. The questionnaire was reliable (Cronbach's alpha 0.946) and had no mis fitting items. The illustrations were well received, and this was reflected on the questionnaire comprehensibility (97.2) and sensitivity to change $(\mathrm{p}<0.01)$.

Conclusions: The illustrated children motivation measure, is a patient-centered unidimensional scale that is valid, reliable and comprehensible. The measure has good psychometric properties and can be used at the individual child's level to tailor management and monitor changes in response to therapy. The illustrations enhanced the questionnaire perception by the children as well as the parents.
\end{abstract}

\section{Introduction}

The development of initiative and autonomy is a critical task of middle childhood and adolescence [1]. As children become less dependent on their parents in facing the daily life challenges, they develop the social and problem-solving skills that form the basis for later successful functioning in adult roles. Juvenile idiopathic arthritis (JIA) is the most common chronic rheumatic disease of childhood. It affects approximately 1 in 1,000 children under the age of 16 years [2]. Children and adolescents with JIA live with chronic or recurrent pain and disability, which can severely limit their ability to complete daily physical tasks and participate in school and social activities $[3,4]$. Consequently, JIA has been acknowledged for its negative impact on the children's psychosocial development. Furthermore, the dynamic nature of the disease, as well as the subjective unique experience which vary amongst children living with JIA, reflect negatively on the children's attitude, psychological status and ability to cope with their day to day lives. This, subsequently, imposes a set of behavioural requirements [5].

In contrast to acute health problems (e.g., infection, injury), where, in most of the cases, straight-forward treatments (e.g., antibiotics) are

${ }^{\star}$ Correspondence to: El Miedany Y, Department of Rheumatology, Darent Valley Hospital, Dartford, UK, E-mail: Yasser_elmiedany@yahoo.com

Key words: children motivation questionnaire, PROMs, adherence, functional ability, quality of life, school

Received: October 13, 2018; Accepted: October 29, 2018; Published: October 31,2018 

motivation

often prescribed and require only moderate levels of patient adherence; chronic diseases, typically require regular monitoring and high levels of adherence to therapy. Furthermore, often there are guidelines and treatment protocols as well as multiple treatment routes from which to choose [6]. The majority of the patients seek care because they want relief from symptoms caused by their disease [7]. When rheumatologists interact with patients their intention is that the partnership they form will motivate patients to engage in self-care which can be incorporated into their lifestyle. It is within this context of a mutually rewarding relationship that motivation and self-care of chronic illness takes place.

According to several prominent behaviour change theories, the action phase, whether for a behaviour or a non-behavioural change, is usually preceded by a motivational stage, in which changes in cognitions lead to formulation of intentions [8]. Self-efficacy and autonomous motivation are two important cognitions in such motivational phase [9]. Self-efficacy is enhanced by successful, positive experiences [10], and this is best achieved by using self-regulation techniques tailored toward small, measurable achievements and by limiting failures when pursuing the goals [11]. Autonomous motivation is the extent to which one might participate in an activity because it is perceived as personally important, as opposed to activation where the person do things for extrinsic reasons (e.g. has been asked to do or to please the others) [12]. As motivation has been linked to more adequate self-care and better management outcomes [13], assessment of the patient motivation may yield better long-term outcomes and disease control.

This study was carried out aiming at the development of a questionnaire for evaluating "motivation" amongst children living with inflammatory arthritic conditions and assess its psychometric properties.

\section{Methods}

\section{Participants}

This was a multicentre study aiming at developing a questionnaire for evaluating the children's "motivation". Targeted population are children and adolescents, age 3-16 years old, diagnosed to have JIA and childhood systemic lupus (cSLE) diagnosed according to the International League of Associations for Rheumatology classification of juvenile idiopathic arthritis (ILAR) [14] as well as the European evidence-based recommendations for diagnosis and treatment of childhood-onset systemic lupus erythematosus [15]. Local ethical and methodological protocols for approval of the study were followed. All the patients participating in the study signed an informed consent according to the Declaration of Helsinki (at the General Assembly in October 2008).

\section{Phase 1A: Conceptualizing motivation}

Based on the critical component for individuals to participate in the management of their chronic conditions [16], a review of the literature [17-22] and discussion with the children/parents groups; children living with JIA who are likely to have better health outcomes were identified as those who: 1 . Understand the nature of their disease, 2. Are involved in the personal care plan; 3 . Are able to maintain functioning, reduce health declines and engaged in activities bearing in mind the dynamicity of the patient's psychological experience and the negative impact of the disease; 4 . Are aware of the patient's healthengagement role and able to share in the decision making process; 5 . Are able to self-manage symptoms/problems particularly in between hospital visits; 6 . Are able to collaborate with treating health care professionals; 7. Can find solutions or make contact to find solution to new problems; 8 . Can adopt lifestyle changes; 9 . Are able to administer medications; 10 . Are able to find resources and select service providers based on performance or quality. These ten domains were used as a frame for an expert consensus and patient focus groups.

\section{Phase 1b: Step I: Developing the item pool}

A random sample of 114 patients (36 JIA, 25 systemic arthritis, 27 enthesitis related arthritis, 26 cSLE; 78 females, and 36 males; mean age 12.2 years \pm 3.28 years, mean disease duration 2.3 years \pm 4.62 years) were interviewed to identify the relevant items pool. Interviews took place in a private room and lasted between 30 minutes- 60 minutes. Related themes were highlighted, grouped together under the domains they were intended to measure and organized by conceptual categories [23-25]. Following a content analysis and cognitive interviews, items were retained and used for the pilot study.

Data regarding the children's age, sex, educational level, school attendance, medical history, physical as well as psychological health activities were collected for each child.

\section{Step II: Development of the questionnaire and psychometric analysis}

One hundred and 35 (135) children (41 JIA, 31 systemic arthritis, 32 enthesitis related arthritis, 31 cSLE; 91 females, and 44 males; mean age 12.6 years \pm 3.19 years, mean disease duration 2.5 years +3.93 years) were included in this step of the work. All participants completed test questionnaire whilst attending the outpatient clinic after a brief introduction letter. A trained nurse was available to help when required. The children's and parents' comments and feedback were recorded. 36-children needed help as they were unable to read the questionnaire. The goal was to obtain a reliable, statistically valid, unidimensional scale that captured as much as possible of the agreed domains derived through the conceptualization stage. Using Rasch analysis, an iterative procedure was used balancing 4 concerns: 1 . removal of miss fitting items, 2 . maximizing scale length, 3. elimination of items with overlapping difficulties, and 4. removal of gaps along the disability-difficulty continuum [26].

Using Rasch analysis, the items that best balanced and met the criteria of item fit, scale length, and were evenly spaced to assess the children's motivation were selected for the questionnaire draft.

Ten questions were identified for the questionnaire, for each question, visual analogue scale (0-10) was used for the patient to score. The score of each questionnaire was the sum of individual item score divided by 10 or the mean of the item score if 8 or 9 items were only completed. The questionnaire was not scored if fewer than 8 items were completed. Total score for each questionnaire ranges from 0-10.

Using visual learning to motivate interactive critical thinking: Based on the fact that visual aids can improve understanding of health risks and treatment options, visual aids have been used whenever it would make the content easier to understand and facilitate independent decision making. Examples: 1. using emojis to make numeric information easier to understand; 2. Illustrated visual aids to reinforce the question meaning and help the children choose their individual preferable answer.

\section{Step III: Validity of the developed questionnaire}

After development of the new illustrated version of the questionnaire, the instrument was assessed for validity, reliability, comprehensibility and user-friendliness as a self-administered questionnaire in a random 

motivation

sample of 142 children (43 JIA, 33 systemic arthritis, 34 enthesitis related arthritis, 32 cSLE; 96 females, and 46 males; mean age 12.3 years \pm 4.53 years, mean disease duration 2.2 years +4.61 years). Fourteen children needed help with reading the questionnaire. Construct validity was assessed by correlating the tool scores to parameters of disease activity: JADAS-27 [27], SLEDAI-2K [28] as well as JSpADA [29]. In addition, each patient completed a patient reported outcome measures questionnaire [30] to identify the child's functional ability, quality of life, school attendance, comorbidities, as well as adherence to medications.

\section{Step IV: Reliability}

The internal consistency reliability of the instrument is a measure of how well the items on a test measure the same construct and is the same as Cronbach's alpha. Reliabilities of $>0.85$ are satisfactory [31,32]. Patients were asked to complete another copy of the questionnaire for a second time after 2 weeks to assess test-retest reliability. This method reduces the influence of information recall associated with shorter periods of retest and produces a more robust estimate of instrument reliability. The intra-class correlation coefficient (ICC) was used to measure agreement between test and retest.

\section{Stage V: Comprehensibility and usefulness}

The final version of the questionnaire was tested for its usefulness and user-friendliness using visual analogue scale $0-100$, where " 0 " represent not at all, whereas "100" represent very much.

\section{Stage VI: Responsiveness}

Responsiveness has been described as "the ability of an instrument to measure clinically important change over time" [33]. The questionnaire sensitivity to change was evaluated in 81 JIA children receiving conventional DMARDS or biologic therapy according to approved guidelines [34]. Patients completed the questionnaire twice in their treatment course; once at 0 -time before starting the medical management and at 6-month after commencing the treatment. Changes in the questionnaire scores were compared to changes of disease activity scores.

\section{Statistical analysis}

Rasch Analysis: the Rasch computer program Winsteps was used in this work [35]. The fit of the data to the model is expressed in 2 ways. First the mean square information-weighted statistic (INFIT) provides information about responses given to items around the same difficulty level as the person's ability. Second, the outlier-sensitive statistic (OUTFIT) refers to items whose difficulty level is remote from the person's ability. An INFIT/OUTFIT range of 0.7-1.3 denotes adequate fit of the data to the model [36,37]. A poor item fit statistic can indicate poorly constructed or understood items or, when a scale score is assigned by a professional lack of reliability in assignment. Otherwise, poor fit may indicate problems with uni-dimensionality, that is, the item does not "belong" to the construct or attribute being measured. In the Rasch model, motivation is considered to lie upon a linear "ruler," similar to an ordinary ruler, where "the lowest possible motivation" is the anchor at one end and "the highest possible motivation" is the anchor at the other end. The motivation range is expressed in logits, a completely linear measure. A question difficulty (threshold) represents the position in logits which the item occupies on the linear disability scale. By plotting the item thresholds for each measure, it was possible to determine the width of the construct covered by each measure and the manner in which the thresholds mark that construct. Finally, the floor and ceiling percent was calculated for each item.
Validation of the questionnaire: Data were presented as frequency tables for categorical variables and mean, standard deviation and $95 \%$ confidence interval for interval variables. Floor percent represent the patient that reported the lowest scale level i.e. showing the lowest motivation. While ceiling is referred to patients reporting highest motivation in their response to the items prescribed. Spearman correlation was used to test correlation of the score calculated with other parameters. Chi-square was used to test association between 2 categorical variables. Cronbach alpha was calculated to test reliability and internal consistency of the questionnaire items. All statistical manipulation and analyses were performed using the 11th version of SPSS.

\section{Results}

Following the review of the literature, the expert consensus process and patients group identified 10-domains for conceptualizing motivation. Six of these domains were identified by experts and patients as key component. These included: knowledge and understanding of the disease nature, personal care, knowledge about medications administration, self-management, problem solving and life style changes. Two components were identified by the patients as primary components, namely collaboration with provider and finding resources. Similarly, 2-components were identified by experts as primary components, namely maintain function and belief in shared decision making. The 4 items were retained for the scale development.

\section{Questionnaire Analysis}

The motivation questionnaire: The 10 items of the questionnaire (Table 1) displayed adequate fit to the Rasch model. This is denoted by 2 fit statistics, INFIT and OUTFIT. For the number of cases in this study, INFIT and OUTFIT values within the range 0.67 to 1.4 represent adequate fit to the model (INFIT ranged from 0.81-1.07, OUTFIT range $0.83-1.14)$. The tasks which came on top of the motivation continuum were: ability to self-manage, life style changes and ability to find solution, ability to maintain functional ability despite tiredness or psychological experience and engage in activities. At the other end of the spectrum came knowledge of disease nature, belief that active involvement in one's health is important as well as shared decision making. Other items held intermediate positions. Table 2 shows the thresholds of all the items included in the questionnaire. The differences

Table 1. The childhood patient motivation questionnaire for measurement of children's and adolescents' motivation

\section{Motivation Questionnaire}

I am aware of the nature of my condition, the reasons for the symptoms, the course it runs and the consequences if left untreated.

I have knowledge of my personal care plan, the treatment options available to me, understand how each treatment I am taking works, and the possible side effects I might get. Regardless of whether I feel down, tired or anxious, I am still able to cope, and not to let my illness stop me from doing things I want to do.

I am aware of my role in my own care, feel able to share in the treatment decision making and know when to seek medical advice.

I would not be worried about discussing any question I may have regarding my condition or treatment with my Doctor/nurse

I am confident I can take any tablet and/or administer any injection prescribed for me. I can self-manage my condition, ease the symptoms and overcome some of the difficulties which might develop in association with my illness between Doctors / hospital visits.

I am happy that I can find a way around any new problem related to my condition, and how to solve it to prevent it from interfering with my every day activities.

I am confident that I will be able to continue with any changes I make to my lifestyle such as diet, work, exercise, drinking or smoking, even if it gets tough.

I am confident I can find reliable and useful sources of information to educate myself about my condition, treatment and health choices 
El Miedany Y (2018) Juvenile inflammatory arthritis: Development and validation of an illustrated questionnaire for measurement of children's and adolescents' motivation

Table 2. Items thresholds of the Patient motivation questionnaire

\begin{tabular}{|l|c|c|c|}
\hline The Motivation Questions & $\begin{array}{c}\text { Item } \\
\text { Threshold }\end{array}$ & Infit & Outfit \\
\hline Collaboration with the provider & 1.93 & 1.5 & 1.36 \\
\hline Ability to find resources & 2.37 & 1.33 & 1.47 \\
\hline Problem solving & 1.57 & 1.23 & 1.36 \\
\hline Life style change & 2.19 & 1.16 & 1.21 \\
\hline Knowledge of disease nature & 1.92 & 1.15 & 1.17 \\
\hline Involvement in Personal care & 1.78 & 1.13 & 1.16 \\
\hline Ability to self-manage & 1.04 & 1.09 & 1.2 \\
\hline Health engagement and shared decision making & 1.25 & 1.03 & 1.09 \\
\hline Knowledge of medication and its administration & 1.06 & 1.03 & 1.05 \\
\hline $\begin{array}{l}\text { Engagement in activities and maintaining } \\
\text { functional ability }\end{array}$ & 1.49 & 0.82 & 0.87 \\
\hline
\end{tabular}

among items, as regards to their difficulty, can also be assessed by percentages of subjects selecting each category of a given item.

\section{Construct and criterion validation outcomes}

Assessment of flooring and ceiling percentages in the developed tool revealed that the mean score was $6.6 \pm 1.4$, percentage of patients at floor was $17.2 \%$ and percentage at ceiling was $23.5 \%$. To assess construct and criterion validity, the 10-item children motivation questionnaire variables, were found to be conceptually related to the children's motivation. They were also examined for their relationship to the measured children's status. The results indicated considerable evidence for the construct validity of the developed measure. Those with higher motivation score report significantly better functional ability $(\mathrm{r}=-0.86, \mathrm{p}<0.001)$, as well as better quality of life $(\mathrm{r}=-0.75$, $\mathrm{p}<0.01)$. Also, they had significantly lower rates of doctor office visits $(r=0.78, p<0.001)$, lower rates of contacting the advice line as well as less number of visits to their general practitioner for matters related to their arthritis $(\mathrm{r}=0.54, \mathrm{p}<0.01)$, whereas they had higher rates of adherence to therapy $(\mathrm{r}=0.86, \mathrm{p}<0.001)$.

Comparison to disease activity scores revealed significant negative relation between the children Motivation questionnaire and the disease activity scores with higher motivation scores correlating significantly with better disease activity control (Table 3 ).

Absence from school was significantly $(\mathrm{p}<0.01)$ negatively related to the children motivation score. Similarly studying the relation between the children motivation questionnaire and the quality of life measure score revealed significant negative relation $(\mathrm{p}<0.01)$.

\section{Reliability}

The children motivation questionnaire was reliable as demonstrated by a relatively high-standardized alpha value $(0.946)$ and minimal changes recorded in the 2 nd from the 1st test. ICC for agreement demonstrated a quite good reliability (ICC 0.95).

\section{Responsiveness}

On studying the correlation of percentage changes in the children motivation questionnaire score to percentage changes of parameters of disease activity, a statistically significant correlation was observed between the developed tool's percentage changes and parameters of disease activity parameters (Table 4 ). The average percentage of change for the children Patient motivation measure was $72.6+27.2$ (95\% CI 61.5-76.7)

\section{Comprehensibility and friendliness}

On a scale from zero to 100 , 'user-friendliness' scored a median of 88 (interquartile range [IQR] 82-96), 'understandability' 89 (IQR
84-97), and 'feeling better informed' 84 (IQR 78-95). The vast majority of patients, $99 \%$ of the assessed children, found the figures added to the questionnaire items were clarifying rather than frightening. $98 \%$ of the patients included reported comprehensibility of $>85 / 100$ (mean comprehensibility rate was $97.2 \pm 0.82$ ).

\section{Discussion}

The implementation of behavioural approaches as an effective way to improve the health of inflammatory arthritis patients, may lead to improved patient outcomes and can be applicable in other populations with chronic diseases. Results of this work revealed that the developed Children Patient Motivation questionnaire (cPMQ) was a valid and reliable tool to measure the child's motivation. The measure has strong psychometric properties in all JIA categories and c-SLE. As the measure was highly reliable at the person level, this facilitates its use on the individual level to evaluate the child's motivation standard and set up care plans tailored to the child's needs. Moreover, as the measure has maintained precision across different disease activity levels, it can also be used at the aggregate level to evaluate and compare the efficacy of health care delivery systems and interventions. Furthermore, results revealed positive association between autonomy support and adherence to therapy as well as improved health related quality of life measures. This agrees with earlier studies including randomized controlled trials which revealed that in different disorders, enhanced self-determined regulations can predict adherence to medical prescriptions [38], smoking cessation [39], weight loss [40], and glycemic control [41] as well as inflammatory arthritis [42]. Other studies have shown that more autonomous motives for exercise correspond to positive outcomes such as adherence [43] and enhanced well-being [44,45].

This study implemented the use of visual aids to conduct the message to the children, which reflected positively on children's perception. This was not only supported by the high comprehensibility and user friendliness scores shown in this study results but was also reinforced by the significant drop of number of children asking for help to complete the questionnaire (dropped by $61 \%$ ). Learning

Table 3. Correlation of the children motivation questionnaire score with the disease activity scores and the patient reported outcomes. JADAS-27: Disease activity score-27, SLEDAI2K: Systemic Lupus Erythematosus Disease Activity Index 2000, JSpADA: Juvenile Spondyloarthritis Disease Activity, HRQoL: Health related quality of life

\begin{tabular}{|c|c|c|}
\hline & Spearman (r) & P value \\
\hline JADAS27 & -0.384 & 0.001 \\
\hline SLEDAI-2K & -0.325 & 0.001 \\
\hline JSpADA & -0.346 & 0.001 \\
\hline $\begin{array}{c}\text { Functional } \\
\text { Disability }\end{array}$ & -0.257 & 0.004 \\
\hline $\begin{array}{c}\text { Health related } \\
\text { QoL }\end{array}$ & -0.284 & 0.001 \\
\hline $\begin{array}{c}\text { Medication } \\
\text { adherence }\end{array}$ & 0.364 & 0.001 \\
\hline
\end{tabular}

Table 4. Correlation of percentage changes of the children motivation score to percentage changes in the disease activity scores as well as patient reported outcomes. ${ }^{* *} \mathbf{P}<\mathbf{0 . 0 1}$ JADAS-27: Disease activity score-27, SLEDAI-2K: Systemic Lupus Erythematosus Disease Activity Index 2000, JSpADA: Juvenile Spondyloarthritis Disease Activity, HRQoL: Health related quality of life.

\begin{tabular}{|c|c|}
\hline Disease Activity Score \% change & Patient Motivation Score \% change \\
\hline JADAS-27 & $0.96^{* *}$ \\
\hline SLEDAI-2K & $0.94^{* *}$ \\
\hline JSpADA & $0.93^{* *}$ \\
\hline Functional Disability & $0.95^{* *}$ \\
\hline HRQoL functional & $0.98^{* *}$ \\
\hline HRQoL psychological & $0.97^{* *}$ \\
\hline
\end{tabular}


theory states that not all students (or patients) learn by reading written information. Visual aids were found a better option for learning; including pictures, illustrations, and cartoons. In addition, the current media dominated learning atmosphere, makes the use of visual aids or any other visual format more attractive to both children and adults. It has been estimated that $65 \%$ of the population are thought to be visual learners - people who retain information better by seeing pictures and videos rather than reading text or hearing information delivered orally [46]. Level of literacy is another factor that favours the use of visual aids. This has been supported by the sobering statistics from the National Assessment of Adult Literacy [47], showing that nearly half of American adults demonstrate low literacy levels, consequently incorporating high-quality visual elements into the patient education materials, not only will improve patients' comprehension of their health and treatment, but also will increase compliance as well, which comes in agreement with the results of this study.

Interventions enhancing the communication between the patient and the health care professional, would have a synergistic impact on the management outcomes and approaches. The developed CPMQ covers 10 categories. Identifying which category, the child might be lacking motivation, can help in handling this challenge by tailoring a program meeting the child's requirements. Motivational text messages can boost health of arthritis patients if they have difficulty with self-management e.g. text messages can be sent to remind the children to take their medicine or have the monitoring blood tests. A study revealed that a combination of text messages and individual counselling sessions to motivate arthritic patients may lead to improved patient outcomes [48]. If there has been a challenge with life style changes or engagement in activities, such approach of behavioural intervention was also reported to be effective at reducing daily sitting time by an average of more than two hours in arthritic patients, and also reduced their cholesterol levels [49]. In cases where there are challenges regarding awareness of the nature of the disease, a recent study showed how implementing USguided patient education could improve the patient motivation and provide those patients with better understanding of the nature of the disease as well as treatment benefits, which in turn made the patients more inclined to accept risks in the pursuit of successful disease control [50].

Self-determination theory (SDT) is a macro theory of human motivation and personality that concerns people's inherent growth tendencies and innate psychological needs [51]. SDT is concerned with the motivation behind choices people make without external influence and interference. JIA disrupts a child's sense of normality and impairs his or her motivation capacity. Children with JIA have a sense of being misunderstood and stigmatized, and they feel perpetually caught between having hope and control over their bodies and overwhelming pain and despair. To increase their confidence and the ability to manage pain, children need ongoing information about treatments, lifestyle management, and active involvement in their own health decision making [52]. Results of this study revealed that by endorsing the children's motivation as a parameter of the disease status, helped to improve the child's quality of life, functional ability, school attendance as well as adherence to therapy.

\section{Conclusion}

In conclusion, this study enforces the patients centred approach for treatment of JIA. The analysis showed that the children Motivation questionnaire has good psychometric properties, is applicable in standard clinical practice and has good correlation with concurrent disease activity measures. It has also solid reliability, sensitivity to change as well as comprehensibility. Having a valid and reliable measure to assess children motivation is the first step in understanding patient proactivity and its role in health care quality, outcomes, and cost containment. This finding may contribute to further development of interventions tailored to the patient's needs.

\section{Conflict of Interest}

The authors have no relevant financial disclosures and has no conflict of interest.

\section{Ethical approval}

All procedures performed in studies involving human participants were in accordance with the ethical standards of the institutional and/ or national research committee and with the 1964 Helsinki declaration and its later amendments or comparable ethical standards. Local ethical and methodological protocols for approval of the study were followed. All patients participating in the study were Egyptians who signed an informed consent according to the Declaration of Helsinki (at the General Assembly in October 2008).

\section{Contributor-ship}

All authors had a substantial contribution to the conception and design of the study, drafting/ revising of the article and final approval of the version to be published.

\section{Acknowledgements}

We express thanks to all participants, our colleagues, research assistants and nurses for their cooperation and help to bring this research to its final conclusions.

\section{References}

1. Power T, Dahlquist L, Thompson S, Warren R (2003) Interactions between children with juvenile rheumatoid arthritis and their mothers. J Ped Psychology 28: 213-221.

2. Ravelli A, Martini A (2007) Juvenile idiopathic arthritis. Lancet 369: 767-768 [Crossref]

3. Adam V, St. Pierre Y, Fautrel B, Clarke AE, Duffy C, et al. (2005) What is the impact of adolescent arthritis and rheumatism? Evidence from a national sample of Canadians. J Rheumatol 32: 354-361.

4. Ding T, Hall A, Jacobs K, David J (2008) Psychological functioning of children and adolescents with juvenile idiopathic arthritis is related to physical disability but not to disease status. Rheumatology 47: 660-664.

5. Billings AG, Moos RH, Miller JJ, Gottlieb JE (1987) Psychosocial adaptation in juvenile rheumatic disease: A controlled evaluation. Health Psychology 6: 343-359.

6. Ringold S, Weiss P, Beukelman T, DeWitt E, Ilowite N, et al. (2013) 2013 Update of the 2011 American College of Rheumatology Recommendations for the Treatment of Juvenile Idiopathic Arthritis. Arthritis Rheum 65: 2499-2512. [Crossref]

7. Patel H, Shafazand M, Schaufelberger M, Ekman I (2007) Reasons for seeking acute care in chronic heart failure. Eur J Heart Fail 9: 702-708. [Crossref]

8. Schwarzer R (2008) Modelling health behavior change: how to predict and modify the adoption and maintenance of health behaviors. Appl Psychol 57: 1-29.

9. Sheeran P, Abraham C (2003) Mediator of moderators: temporal stability of intention and the intention-behavior relation. Pers Social Psychol B 29: 205-215. [Crossref]

10. Knittle K, De Gucht V, Hurkmans E, Peeters A, Ronday K, et al. (2013) Targeting motivation and self-regulation to increase physical activity among patients with rheumatoid arthritis: a randomized controlled trial. Clin Rheumatol 34: 231-238. [Crossref]

11. Warner LM, Schüz B, Knittle K, Ziegelmann JP, Wurm S (2011) Sources of perceived self-efficacy as predictors of physical activity in older adults. Appl Psychol: Health Well-Being 3: 172-192. 
El Miedany Y (2018) Juvenile inflammatory arthritis: Development and validation of an illustrated questionnaire for measurement of children's and adolescents' motivation

12. Bandura A (1994) Self-efficacy. In Ramachaudran VS (Ed), Encyclopedia of human behavior. New York: Academic Press 4: 71-81.

13. Ryan RM, Deci EL (2000) Intrinsic and extrinsic motivations: classic definitions and new directions. Contemp Educ Psychol 25: 54-67.

14. Petty RE, Southwood TR, Manners P (2004) International League of Associations for Rheumatology classification of juvenile idiopathic arthritis: second revision Edmonton, 2001. J Rheumatol 31: 390-392. [Crossref]

15. Groot N, Graeff ND, Avcin T, Bader-Meunier B, Brogan P, et al. (2017) European evidence-based recommendations for diagnosis and treatment of childhood-onset systemic lupus erythematosus: the SHARE initiative. Ann Rheum Dis 76: 1788-1796.

16. Jordan J, Briggs A, Brand C, Osborne R (2008) Enhancing patient engagement in chronic disease self-management support initiatives in Australia: the need for an integrated approach. MAJ 189: S9-S13.

17. Von Korff M, GrumanJ, Schaefer J, Curry SJ, Wagner EH (1997) Collaborative Management of Chronic Illness. Ann Intern Med 127: 1097-1102. [Crossref]

18. Lorig K, Sobel D, Stewart A, Brown B, Bandura A, et al. (1999) Evidence suggesting that a chronic disease self-management program can improve health status while reducing hospitalization: A Randomized Trial. Medical Care 37: 5-14. [Crossref]

19. Von Korff J, Moore E, Lorig K, Cherkin D, Saunders K, et al. (1998) A randomized trial of a lay person-led self-management group intervention for back pain patients in primary care. Spine 23: 2608-2615. [Crossref]

20. Bodenheimer T, Lorig K, Holman H, Grumbach K (2002) Patient self-management of chronic disease in primary care. JAMA 288: 2469-2475. [Crossref]

21. Hibbard J, Stockard J, Mahoney E, Tusler M (2002) Development of the patient activation measure (pam): conceptualizing and measuring activation in patients and consumers. Health Services Res 39: 1005-1026. [Crossref]

22. Daltroy L, Liang M (1991) Advances in patient education in rheumatic disease. Ann Rheum Dis 50: 415-417.

23. Ruta DA, Garratt AM, Russell IT (1999) Patient centered assessment of quality of life for patients with four common conditions. Qual Health Care 8: 22-29. [Crossref]

24. Bowling A (1997) Research methods in health. Investigating health and health services. Buckingham, UK: Open University Press.

25. Garratt AM, Ruta DA (1999) The Patient Generated Index. In: Joyce CRB, O’Boyle CA, McGee HM (eds). Individual quality of life: Approaches to conceptualisation and assessment. Amsterdam Harwood Academic Publishers 105-118.

26. Linacre JM, Wright BD (1977) A user's guide to BIGSTEPS: Rasch model computer program (version 2.8). Chicago: Mesa Press

27. Consolaro A, Ruperto N, Bazso A, Pistorio A, Magni-Manzoni S, et al. (2009) Development and validation of a composite disease activity score for juvenile idiopathic arthritis. Arthritis Rheum 61: 658-666. [Crossref]

28. Gladman DD, Ibañez D, Urowitz MB (2002) Systemic lupus erythematosus disease activity index 2000. J Rheumatol 29: 288-291. [Crossref]

29. Weiss PF, Colbert RA, Xiao R, Feudtner C, Beukelman T, et al. (2014) Development and retrospective validation of the juvenile spondyloarthritis disease activity index. Arthritis Care Res (Hoboken) 66: 1775-1782. [Crossref]

30. El Miedany Y, Lotfy H, El Aroussy N, Mekkawy D, Nasef SI, et al. (2018) Facilitating patient centred care: the development of illustrated multidimensional patient reported outcome measure for children with juvenile idiopathic arthritis. Ann Rheum Dis 77: A502.

31. Cronbach LJ (1951) Coefficient alpha and the internal structure of tests. Psychomtrika 16: 297-334.

32. Carr AJ (1996) A patient-centred approach to evaluation and treatment in rheumatoid arthritis: the development of a clinical tool to measure patient-perceived handicap. $\mathrm{Br}$ J Rheumatol 35: 921-932.
33. Fitzpatrick R, Davey C, Buxton MJ, Jones DR (1998) Evaluating patient-based outcome measures for use in clinical trials. Health Technol Assess 2: 1-74. [Crossref]

34. Atef Y, Lotfy H, El Aroussy N, Mekkawy D, Hassan M, Nasef S, et al. (2018) Guidelines for juvenile idiopathic arthritis management: is there a room for combined methotrexate and leflunomide therapy in the treatment recommendations. Ann Rheum Dis 77: 480 .

35. Linacre JM (1999) Understanding Rash measurement: estimation methods for Rasch measures. J Outcome Meas 3: 382-405. [Crossref]

36. Prieto L, Alonso J, Lamarca R, Wright BD (1998) Rasch measurement for reducing the items of the Nottingham Health Profile. J Outcome Meas 2: 285-301. [Crossref]

37. Smith RM, Schumacher RE, Bush MJ (1998) Using item mean squares to evaluate fit in the Rasch model. J Outcome Meas 2: 66-78.

38. Williams GC, Deci EL (1998) The importance of supporting autonomy in medical education. Ann Int Med 129: 303-308. [Crossref]

39. Williams GC, Gagne M, Ryan RM, Deci EL (2002) Facilitating autonomous motivation for smoking cessation. Health Psychol 21: 40-50. [Crossref]

40. Williams GC, Grow VM, Freedman ZR, Ryan RM, Deci EL (1996) Motivational predictors of weight loss and weight-loss maintenance. J Pers Soc Psychol 70: $115-$ 126. [Crossref]

41. Williams GC, McGregor HA, Zeldman A, Freedman ZR, Deci EL (2004) Testing self-determination theory process model for promoting glycemic control through diabetes self-management. Health Psychol 23: 58-66. [Crossref]

42. Miedany Y El, Gaafary M El, Youssef S, Elaroussy N (2017) Meaningful patient engagement in inflammatory arthritis: development of the Patient Motivation Questionnaire. Clin Rheumatol 36: 1-9. [Crossref]

43. Edmunds J, Ntoumanis N, Duda JL (2008) Testing a self-determination theory-based teaching style in the exercise domain. Eur J Soc Psychol 38: 375-388.

44. Duda JL, Williams GC, Ntoumanis N, Daley A, Eves FF, et al. (2014) Effects of a standard provision versus an autonomy supportive exercise referral programme on physical activity, quality of life and well-being indicators: a cluster randomised controlled trial. Int J Behav Nutr Phys Act 11: 10-15.

45. Rouse PC, Veldhuijzen Van Zanten JJ, Metsios GS (2014) BMC Musculoskeletal Disord 15: 445 .

46. Gossec L, Smolen JS, Ramiro S, de Wit M, Cutolo M, Dougados M, et al. (2016) European League Against Rheumatism (EULAR) recommendations for the management of psoriatic arthritis with pharmacological therapies: 2015 update. Ann Rheum Dis 75: 499-510. [Crossref]

47. Bradford, William C (2004) Reaching the Visual Learner: Teaching Property Through Art. Law Teacher p. 11.

48. Hughes L, Russell B, Jenkins S, Done D, Young J (2012) Do patients with rheumatoid arthritis want SMS text messages to remind them about hospital appointments and drug adherence? Rheumatology (suppl) 51: 65.

49. Frank J Schwebel, Mary E Larimer, (2018) Using text message reminders in health care services: A narrative literature review. Invent 2018.

50. Miedany YM El, Gaafary M El, Aroussy N El, Youssef S, Palmer D (2017) Patient motivation in inflammatory arthritis: The use of ultrasound-guided patient education to endorse medication adherence and facilitate cost-effective targeted management [abstract]. Arthritis Rheumatol p. 69.

51. Ryan RM, Deci EL (2002) Self-determination theory and the facilitation of intrinsic motivation, social development, and well-being. American Psychologist 55: 68-78.

52. Bodenheimer T, Lorig K, Holman H, Grumbach K (2002) Patient self-management of chronic disease in primary care. JAMA 288: 2469-2475. [Crossref]

Copyright: $@ 2018 \mathrm{El}$ Miedany Y. This is an open-access article distributed under the terms of the Creative Commons Attribution License, which permits unrestricted use, distribution, and reproduction in any medium, provided the original author and source are credited. 